\title{
THE FRONTAL CARDIAC SILHOUETTE IN OLDER PEOPLE
}

\author{
BY \\ NAIRN R. COWAN \\ From the Consultative Health Centre for Older People, Rutherglen, Lanarkshire
}

Received April 2, 1964

In this study measurements of the frontal cardiac silhouette are presented in persons aged 60 to 79 years, using x-ray films of the chest, together with data on their body weight, frontal chest area, kyphotic angle, and systolic blood pressure. Diastolic blood pressure was no more effective than systolic blood pressure and is omitted, as also is stature, which is a rather poor correlative in older years. The nature and intensity of the relations of the cardiac area with these other factors are assessed, and the efficiency with which the cardiac area can be predicted from a knowledge of such variables is indicated. The influence of age is shown by contrasting the findings for adjacent decennial periods 60 to 69 and 70 to 79 years.

\section{SubJeCts AND Methods}

The data are derived from the records of 139 men and 167 women, aged 60 to 69 years, and 163 men and 133 women, aged 70 to 79 years: all attended the Rutherglen Consultative Health Centre for older people (Anderson and Cowan, 1955). They were considered to be in good health after a thorough clinical examination which included ophthalmoscopic examination and where necessary electrocardiographic assessment. Excluded from this series were those with hæmoglobin under $11 \mathrm{~g}$. Sahli, or an apical systolic murmur louder than Grade 2 as described by Levine and Harvey (1949).

A planimeter calibrated in square centimetres was used to measure the areas of the frontal cardiac silhouette and chest. In measuring the chest area the outline followed by the planimeter was formed by commencing at the right costophrenic angle and moving upwards along the internal aspect of the ribs on the right side; horizontally along the lower border of the posterior part of the first or second ribs whichever was at the higher level; downwards along the internal aspect of the ribs on the left side to the left costophrenic angle, and to the point of commencement following the margins of left dome of diaphragm, lower aspect of cardiac silhouette, and right dome of diaphragm. The x-ray films used were taken in the postero-anterior position during held inspiration at a distance of two metres.

Lateral x-ray chest films taken at a distance of two metres were used to measure the kyphotic angle. A straight line was drawn downwards through the mid-points of the anterior margins of the second and third thoracic vertebrae. Another straight line was drawn upwards through the mid-points of the anterior margins of the 12th and 11th thoracic vertebræ. These two lines always intersect, and the superior angle formed by the intersection of these lines is recorded as the kyphotic angle and is measured in degrees.

Weight was measured to the nearest quarter pound $(120 \mathrm{~g}$.). The men and women wore a minimum of clothing and no footwear.

Arterial blood pressure was estimated by the auscultatory method to the nearest even number using a mercury manometer with standard cuff. Systolic blood pressure was recorded at the point at which sounds were first heard, and diastolic blood pressure at the point of sudden muffling which occurs before the disappearance of the sounds. 
TABLE I

Means, Standard Deviations, and Coefficients of Variation of the several Variables by Sex and Ten-year AGE-GROUPS

\begin{tabular}{|c|c|c|c|c|c|c|c|}
\hline \multirow{2}{*}{$\begin{array}{l}\text { Age-group and } \\
\text { number of men and } \\
\text { women }\end{array}$} & \multirow[t]{2}{*}{ Variable } & \multicolumn{2}{|c|}{ Mean \pm standard error } & \multicolumn{2}{|c|}{ Standard deviation } & \multicolumn{2}{|c|}{$\begin{array}{l}\text { Coefficient of } \\
\text { variation }\end{array}$} \\
\hline & & Men & Women & Men & Women & Men & Women \\
\hline \multirow{5}{*}{$60-69 ; 139 \mathrm{M}, 167 \mathrm{~F}$} & \multirow{5}{*}{$\begin{array}{l}\text { Frontal cardiac area } \\
\text { (sq. cm.) } \\
\text { Weight (lb.) } \\
\text { Frontal chest area } \\
\text { (sq. cm.) } \\
\text { Kyphotic angle } \\
\text { (degrees) } \\
\text { Systolic blood } \\
\text { pressure (mm. } \mathrm{Hg} \text { ) }\end{array}$} & $122 \cdot 2 \pm 1 \cdot 03$ & $110 \cdot 4 \pm 0.93$ & $12 \cdot 1$ & $12 \cdot 0$ & $9 \cdot 9$ & $10 \cdot 9$ \\
\hline & & $140 \cdot 3 \pm 1 \cdot 87$ & $147 \cdot 8 \pm 2 \cdot 32$ & $22 \cdot 1$ & $30 \cdot 0$ & $15 \cdot 7$ & $20 \cdot 3$ \\
\hline & & $636 \cdot 0 \pm 6 \cdot 47$ & $476 \cdot 3 \pm 4 \cdot 50$ & $76 \cdot 3$ & $58 \cdot 2$ & $12 \cdot 0$ & $12 \cdot 2$ \\
\hline & & $42.6 \pm 1.06$ & $50.0 \pm 1.04$ & $12 \cdot 5$ & $13 \cdot 5$ & $29 \cdot 3$ & $27 \cdot 0$ \\
\hline & & $154 \cdot 8 \pm 1 \cdot 78$ & $167 \cdot 5 \pm 2 \cdot 19$ & $21 \cdot 0$ & $28 \cdot 3$ & $13 \cdot 6$ & $16 \cdot 9$ \\
\hline \multirow{4}{*}{$70-79 ; 163 \mathrm{M}, 133 \mathrm{~F}$} & \multirow{4}{*}{$\begin{array}{l}\text { Frontal cardiac area } \\
\text { (sq. cm.) } \\
\text { Weight (lb.) } \\
\text { Frontal chest area } \\
\text { (sq. cm.) } \\
\text { Kyphotic angle } \\
\text { (degrees) } \\
\text { Systolic blood } \\
\text { pressure (mm. Hg) }\end{array}$} & $\begin{array}{l}124 \cdot 2 \pm 1 \cdot 05 \\
138 \cdot 3 \pm 1 \cdot 47\end{array}$ & $\begin{array}{l}107 \cdot 4 \pm 1 \cdot 01 \\
136 \cdot 5 \pm 2 \cdot 35\end{array}$ & $\begin{array}{l}13 \cdot 4 \\
18 \cdot 8\end{array}$ & $\begin{array}{l}11 \cdot 7 \\
27 \cdot 1\end{array}$ & $\begin{array}{l}10 \cdot 8 \\
13 \cdot 6\end{array}$ & $\begin{array}{l}10 \cdot 9 \\
19 \cdot 8\end{array}$ \\
\hline & & $618 \cdot 6 \pm 6 \cdot 21$ & $457 \cdot 9 \pm 5 \cdot 11$ & $79 \cdot 3$ & $58 \cdot 9$ & $12 \cdot 8$ & $12 \cdot 9$ \\
\hline & & $49 \cdot 3 \pm 1 \cdot 22$ & $55 \cdot 8 \pm 1 \cdot 15$ & $13 \cdot 6$ & $13 \cdot 3$ & $27 \cdot 6$ & $23 \cdot 8$ \\
\hline & & $164 \cdot 2 \pm 1 \cdot 70$ & $181 \cdot 3 \pm 2 \cdot 32$ & $21 \cdot 7$ & $26 \cdot 8$ & $13 \cdot 2$ & $14 \cdot 8$ \\
\hline
\end{tabular}

\section{RESULTS}

Table I shows for each sex the means with their standard errors, the standard deviations, and the coefficients of variation of the several variables for two decennial age-groups. The cardiac area of the men is on average greater than that of the women by $11.8 \mathrm{sq} . \mathrm{cm}$. in the seventh decade and $16.8 \mathrm{sq} . \mathrm{cm}$. in the eighth decade. Diminution in average body weight is rather more pronounced in women. Chest area decreases in both sexes with age. Kyphosis, which is more marked in women, increases in both sexes with age. The average systolic blood pressure of the women is greater than the corresponding value for the men in each age-group, and the systolic blood pressure increases in both sexes with age.

The absolute and relative variabilities of cardiac area (measured by the standard deviation and coefficient of variation respectively) are less than the corresponding values of the independent variables. Both variabilities are similar for the two sexes, and are uninfluenced by age.

The relative variability of the cardiac area in the two age-groups is 10.9 for women and 9.9 and 10.8 for men. These levels are moderate but greater than the 8.9 of the transverse heart diameter (Cowan, 1960) and the 7.7 of the cardiothoracic ratio (heart-lung coefficient; Cowan, 1959).

The coefficients of correlation for the four age-sex groups for each pair of variables were calculated (Table II). The closest relations between cardiac area and other variables for men are those involving chest area and kyphotic angle. In men weight and systolic blood pressure each show a non-significant association with the cardiac area. Women, however, reveal significant associations between the cardiac area and all independent variables. In both sexes the association between cardiac area and kyphotic angle is significant and negative in sign. These coefficients of correlation do not take into account the interrelations that exist in varying degree between the variables themselves, and in consequence do not measure the strength of association between the cardiac area and each of the other variables when the influence of the remaining independent variables has been eliminated. This is measured by coefficients of partial correlation between cardiac area and each of the other variables taken separately, one or more of the remainder being held constant. The third order coefficients of correlation (Table III) indicate that when the three residual variables are 
TABLE II

Partial Correlations, Area of Frontal Cardiac Silhouette, and Zero Order Coefficients by SeX and Ten-year AGE-GROUPS

\begin{tabular}{c|c|c|c|c}
\hline \multirow{3}{*}{ Subscripts } & \multicolumn{4}{|c}{ Zero order correlation coefficients } \\
\cline { 2 - 5 } & \multicolumn{3}{|c|}{ Men } & \multicolumn{2}{c}{ Women } \\
\cline { 2 - 5 } & $60-69$ years & $70-79$ years & $60-69$ years & $70-79$ years \\
\hline 12 & 0.1539 & 0.1380 & $0.3943 \dagger$ & $0.4159 \dagger$ \\
13 & $0.6497 \dagger$ & $0.7122 \dagger$ & $0.5810 \dagger$ & $0.5872 \dagger$ \\
14 & $-0.5887 \dagger$ & $-0.4441 \dagger$ & $-0.3163 \dagger$ & $-0.3514 \dagger$ \\
15 & -0.1719 & -0.0868 & $0.3424 \dagger$ & $0.2387 \dagger$ \\
23 & 0.0355 & 0.0652 & -0.0972 & 0.1011 \\
24 & 0.0728 & -0.0114 & 0.0150 & -0.0938 \\
25 & 0.0555 & 0.0924 & $0.5267 \dagger$ & $0.2766 \dagger$ \\
34 & $-0.3464 \dagger$ & $-0.5081 \dagger$ & $-0.3486 \dagger$ & $-0.4717 \dagger$ \\
35 & $-0.2349 \dagger$ & $-0.1952 *$ & -0.0789 & -0.0475 \\
45 & 0.1597 & 0.0472 & 0.1155 & -0.0256 \\
\hline
\end{tabular}

The subscripts are: 1 , area of cardiac silhouette; 2 , weight; 3 , frontal chest area; 4 , kyphotic angle; and 5, systolic blood pressure.

The significance of the coefficients is assessed from Table 7.6.1, p. 174 in Statistical Methods, Snedecor, G. W. 5th edition. The Iowa State College Press, Iowa.

* 5 per cent level of significance.

$\dagger 1$ per cent level of significance.

TABLE III

Partial Correlations, Area of Frontal Cardiac Silhouette, Third Order Coefficients by SeX and Ten-year AGE-GROUPS

\begin{tabular}{c|c|c|c|c}
\hline \multirow{3}{*}{ Subscripts } & \multicolumn{4}{|c}{ Third order correlation coefficients } \\
\cline { 2 - 5 } & \multicolumn{3}{|c}{ Men } & \multicolumn{2}{c}{ Women } \\
\cline { 2 - 5 } & $60-69$ years & $70-79$ years & $60-69$ years & \multicolumn{1}{|c}{$70-79$ years } \\
\hline 12.345 & $0.2543 \dagger$ & 0.1291 & $0.4120 \dagger$ & $0.3842 \dagger$ \\
13.245 & $0.5841 \dagger$ & $0.6263 \dagger$ & $0.6472 \dagger$ & $0.5539 \dagger$ \\
14.235 & $-0.5348 \dagger$ & -0.1371 & $-0.2084 \dagger$ & $-0.0830 \dagger$ \\
15.234 & 0.0060 & 0.0543 & $0.2904 \dagger$ & $0.2351 \dagger$ \\
\hline
\end{tabular}

The subscripts have the same meaning as those in Table II.

The significance of the coefficients is assessed from Snedecor's Table 7.6.1.

+ Significant at 1 per cent level.

held constant, (a) the significance of the correlations between the cardiac area and each variable is diminished except for the association between cardiac area and weight for men and women in the age-groups 60-69 years, and cardiac area and chest area for women only in the same age-group, (b) in men chest area and kyphotic angle are the most important correlatives of cardiac area for the age-group 60-69 years, while this applies only to chest area for the age-group 70-79 years, in women chest area and weight are the most important correlatives of cardiac area in both decennial age periods; (c) the strength of association in women is less in the later than in the earlier decade, though only the correlation between cardiac area and kyphotic angle is rendered non-significant in the later age period. In men the strength of association is less in the later than in the earlier decade for the variables weight and kyphotic angle, which both become non-significant, is enhanced in the later decade for chest area, and remains non-significant for systolic blood pressure.

In view of the decided association between these other attributes and cardiac area the high initial variability of this area (Table I) can clearly be reduced when a knowledge of these other variables is 
TABLE IV

Partial Standard Deviations for the Area of the Frontal Cardiac Silhouette by Sex and Ten-year AgeGROUPS WITH REFERENCE TO ALL OTHER VARIABLES

\begin{tabular}{c|c|c|c|c}
\hline \multirow{3}{*}{ Subscript } & \multicolumn{4}{|c}{ Partial standard deviations } \\
\cline { 2 - 5 } & \multicolumn{2}{|c|}{$60-69$ years } & \multicolumn{2}{c}{$70-79$ years } \\
\cline { 2 - 4 } & Men & Women & Men & Women \\
\hline 1 with 2345 & 7.65 & 7.63 & 9.24 & 8.22 \\
\hline
\end{tabular}

The subscripts have the same meaning as those in Table II.

TABLE V

Coefficients of Multiple Correlation by SeX and Ten-year Age-Groups

\begin{tabular}{|c|c|c|c|c|}
\hline \multirow{3}{*}{ Subscripts } & \multicolumn{4}{|c|}{ Coefficients of multiple correlation } \\
\hline & \multicolumn{2}{|c|}{ 60-69 years } & \multicolumn{2}{|c|}{$70-79$ years } \\
\hline & Men & Women & Men & Women \\
\hline $\begin{array}{l}1 \cdot 23 \\
1 \cdot 34 \\
1 \cdot 2345\end{array}$ & $\begin{array}{l}0.7565 \\
0.7747\end{array}$ & $\begin{array}{l}0.7367 \\
0.7726\end{array}$ & $\begin{array}{l}0.7186 \\
0.7257\end{array}$ & $\begin{array}{l}0.6879 \\
0.7116\end{array}$ \\
\hline
\end{tabular}

The subscripts have the same meaning as those in Table II.

available. The extent of this reduction when such a knowledge is utilized is apparent on comparison of the partial standard deviations (Table IV) with the initial crude values (Table I). They show that for constant weight, chest area, kyphotic angle, and systolic blood pressure, the absolute variability of the cardiac area is reduced by 37 per cent and 36 per cent for men and women respectively in the earlier, and by 31 per cent and 30 per cent for men and women respectively in the later age-group.

A further point to determine is the relative strength of the association between the cardiac area and the various combinations of the independent variables. This is found by comparison of the coefficients of multiple correlation (Table V). The salient feature is that for men in both age-groups

TABLE VI

\begin{tabular}{|c|c|c|c|c|c|}
\hline & & & & & $\begin{array}{l}\text { Percentage efficiency } \\
\text { of prediction }\end{array}$ \\
\hline 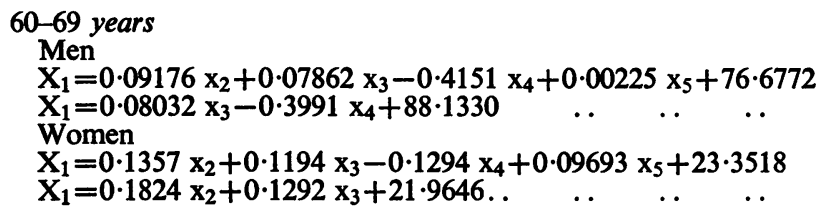 & $\begin{array}{l}\cdots \\
\cdots \\
\cdots\end{array}$ & $\begin{array}{l}\cdots \\
\cdots \\
\cdots \\
\cdots\end{array}$ & $\begin{array}{l}\cdots \\
\cdots \\
\cdots\end{array}$ & $\begin{array}{l}\cdots \\
\cdots \\
\cdots \\
\cdots\end{array}$ & $\begin{array}{l}37 \\
35 \\
36 \\
32\end{array}$ \\
\hline 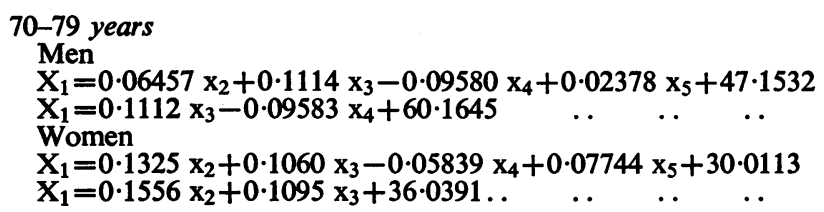 & $\begin{array}{l} \\
\ldots \\
\ldots \\
\ldots\end{array}$ & $\begin{array}{l}\cdots \\
\cdots \\
\ldots\end{array}$ & $\begin{array}{l}\cdots \\
\cdots \\
\ldots\end{array}$ & $\begin{array}{l}\ldots \\
\cdots \\
\ldots\end{array}$ & $\begin{array}{l}31 \\
30 \\
\\
30 \\
27\end{array}$ \\
\hline
\end{tabular}

$X_{1}=$ cardiac area (sq. cm.), $x_{2}=$ weight (lb.), $x_{3}=$ chest area (sq. cm.), $x_{4}=$ kyphotic angle (degrees), and $x_{5}=$ systolic blood pressure. 
the coefficients of multiple correlation involving chest area and kyphotic angle are little less than the corresponding coefficients involving all four independent variables. For women in both age-groups the coefficients of multiple correlation involving weight and chest area are little less than the corresponding coefficients involving all four independent variables.

Equations predicting cardiac area in terms of all four independent variables and also in terms of the variables which are little less efficient in predictive value are given in Table VI.

The prediction equation for cardiac area based on age, height, and weight of Hodges and Eyster (1924) is in error when applied to older people. Over 60 years the cardiac area does not increase with age, and height is a rather poor correlative.

\section{SUMMARY}

The area of the frontal cardiac silhouette in 602 healthy old people, aged 60 to 79 years, is examined and related to the other attributes, body weight, frontal area of chest, kyphotic angle, and systolic blood pressure.

The average cardiac area shows no increase with age. The relative variability of approximately 11.0 is moderate but is greater than the 8.9 of the transverse heart diameter and the $7 \cdot 7$ of the heartlung coefficient.

The cardiac area is related most appreciably with the frontal area of chest and kyphotic angle in men, and with body weight and frontal area of chest in women.

Multiple regression equations are presented predicting the cardiac area in terms of all four independent variables and in terms of the most important variables. The predictive efficiency of the equations is about 30 per cent.

The work described in this paper is included in a Ph.D. thesis (Glasgow University, 1962).

Acknowledgement is made to the Secretary of State for Scotland for a grant provided on the recommendation of the Advisory Committee on Medical Research.

\section{REFERENCES}

Anderson, W. F., and Cowan, N. R. (1955). A consultative health centre for older people. Lancet, $2,239$. Cowan, N. R. (1959). The heart-lung coefficient in older people. Brit. Heart J., 21, 238. (1960). The transverse diameter of the heart in older people. Brit. Heart J., 22, 391.

Hodges, P. C., and Eyster, J. A. E. (1924). Estimation of cardiac area in man. Amer. J. Raentgenol., $12,252$. Levine, S. A., and Harvey, W. P. (1949). Clinical Auscultation of the Heart, p. 145. Saunders, Philadelphia. 